Original Article

\title{
CHEMICAL MODIFICATION, CHARACTERIZATION AND EVALUATION OF MUCOADHESIVE POTENTIALITY OF ASSAM BORA RICE STARCH
}

\author{
ABDUL BAQUEE AHMEDa*, IMAN BHADURI \\ aGirijananda Chowdhury Institute of Pharmaceutical Science, Azara, Guwahati 781017, India, bM. Pharm., Department of Pharmaceutics, \\ Girijananda Institute of Pharmaceutical Sciences, Azara, Guwahati, Assam 781017, India
} Email: baquee1977@gmail.com

Received: 19 May 2017 Revised and Accepted: 13 Jul 2017

\section{ABSTRACT}

Objective: The objective of the present study was to chemical modification, characterization and evaluation of mucoadhesive potentiality of Assam bora rice starch as potential excipients in the sustained release drug delivery system.

Methods: The starch was isolated from Assam bora rice and esterified using thioglycolic acid and characterized by Fourier transform infrared spectroscopy (FT-IR), Differential scanning calorimetry (DSC) and Nuclear magnetic resonance (NMR). The 10\% w/v gel formulation based on modified bora rice starch loaded with irinotecan $(0.6 \%)$ was prepared and evaluated for various rheological properties, ex-vivo mucoadhesion using goat intestine and in vitro drug release study in phosphate buffer $\mathrm{pH} 6.8$.

Results: The chemical modification was confirmed by FT-IR and NMR studies with the presence of the peak at $2626.74 \mathrm{~cm}^{-1}$ and a singlet at 2.51 respectively due to-SH group. Ex-vivo mucoadhesion studies showed 6.6 fold increases in mucoadhesion of the modified starch with compared to native starch $(46.3 \pm 6.79 \mathrm{~g}$ for native starch; $308.7 \pm 95.31 \mathrm{~g}$ for modified starch). In vitro study showed $89.12 \pm 0.84 \%$ of drug release after $6 \mathrm{~h}$ in phosphate buffer $\mathrm{pH} 6.8$ and the release kinetics followed Non-Fickian diffusion.

Conclusion: The modified Assam bora rice starch enhanced a mucoadhesive property of the native starch and thus, can be explored in future as a potential excipient for the sustained release mucoadhesive drug delivery system.

Keywords: Assam bora rice starch, Ex-vivo mucoadhesion, Modified starch, In vitro drug release

(c) 2017 The Authors. Published by Innovare Academic Sciences Pvt Ltd. This is an open access article under the CC BY license (http://creativecommons.org/licenses/by/4.0/) DOI: http://dx.doi.org/10.22159/ijpps.2017v9i9.20108

\section{INTRODUCTION}

The bioadhesion is the term that refers to any kind of bond formed either between two biological surfaces or between a biological and a synthetic surface. Since the concept of bioadhesion is coming into light a lot of attempts were taken to improve the adhesive property of the polymer. The Mucoadhesive polymers which form noncovalent bonds such as hydrogen bonds, van der Waal's forces, and ionic interactions have weak bioadhesion [1]. The mucoadhesive delivery systems gain the superiority by having some advantages over conventional systems such as-mucoadhesive delivery systems can be eagerly delivered on the site of action, this kind of systems allow for intimate contact of the formulation with the mucosal surface that enhance the permeability for macromolecules, also these delivery systems can lengthen the residence period at the employed site of the dosage form [2, 3]. Thiolated polymers or thiomers covalently anchor with mucus by disulphide bonds and can mimic the natural mechanism of secreted mucus glycoprotein. The cysteine rich sub domain of mucus glycoprotein undergoes thiol/disulphide exchange reaction and forms disulphide bonds between polymer and mucus layer $[4,5]$.

Thiolated polymers can be prepared by interacting the thiol moieties, with the established polymers (hydrophilic) like chitosan [6], poly-(acrylates) [7]. Apart from having a strong mucoadhesive property also have advantages as prolonged residential time of delivery, prevention to adhesive bond failure, reduction in side effects as well as a cost; also thiomers has permeation enhancing and enzyme inhibitory properties. Thiolation has been done in several polymers and polysaccharides like chitosan.

Rice is widely grown, consumed and important cereal crop in India. Rice generally contains two types of starch components-Amylose and Amylopectin. The amount of each starch component determines the texture of the cooked rice and whether it will be fluffy, creamy or sticky. Chemically starches are polysaccharide and composed of monosaccharide or sugar molecules linked together with $\alpha$-D-(1-4) and/or $\alpha$-D-(1-6) linkages. The Bora rice chemically can be characterized by the lack of amylose content and the highest amount of amylopectin. Bora rice is also known as sticky rice or glutinous rice is a short-grain, Asian varietal that is used in many cuisines for its characteristic sticky texture and also possess a good gelling property $[8,9]$. It's only when the conditions are right that the rice starch molecules can break apart, causing the structure of the grain to become soft, mushy and sticky [10]. During the Ahom reign in Assam Bora rice with egg was used in constructing buildings only because of its sticky quality.

As this selective polysaccharide has its bioadhesive nature, it can be used as a drug delivery system for targeted and optimal drug delivery due to the intimacy and duration of contact [11, 12]. Still, Native starches cannot achieve enough stability under shear, acidic condition, retrogradation tendency, thermal decomposition; also cannot provide enough adhesiveness due to the weak bond formation. Sometimes solubility (in cold-water) and mechanical properties (lower flexibility and tensile strength) also limits its applications [13]. To overcome these limitations or to utilize these drawbacks as our advantage starch modification is necessary [14]. Generally, starch modification involves alteration of physicochemical characteristics of the starch. Chemical modification leads to increase in hydrophobic or hydrophilic or mucoadhesive property or may be some other changes through esterification, etherification, thiolation, cross linking, acid modification etc. Also starch could be modified

The present study was designed with the aim to improve the mucoadhesive property of the Bora rice starch by thiol treatment and to characterize by Differential Scanning Calorimetry (DSC), Fourier Transform Infra-Red Spectroscopy (FTIR) and Nuclear Magnetic Resonance (NMR). The thiolated starch was further explored for mucoadhesive application by formulating a gelling system with irinotecan as a model drug and evaluated for various parameters such as ex-vivo bio-adhesion and rheological properties. 


\section{MATERIALS AND METHODS}

\section{Materials}

Assam Bora Rice was collected from the local market of Dibrugarh district of upper Assam, India. Irinotecan was obtained as a gift sample from Emcure Pharmaceuticals Limited (Pune, India). Thioglycolic acid and Triethanolamine was procured from Sisco Research Laboratory Pvt. Ltd. (New Mumbai). Carbopol 934P were purchased from Yarrow Chem. Products (Mumbai, India) respectively. Freshly excised goat intestine was obtained from the local butcher shop (Azara, Guwahati). All other chemicals used were of analytical grade.

\section{Isolation of starch from Assam bora rice}

Rice was fully milled in a laboratory miller and then passed through a screen with $125 \mu \mathrm{m}$ openings to filter the flour particles after being milled. The flour (66g) was then suspended in a $0.25 \% 240 \mathrm{ml} \mathrm{NaOH}$ (pH 11) solution with continuous stirring and allowed to soak for 30 min. The rice flour was then blended at $15,000 \mathrm{rpm}$ for $20 \mathrm{~min}$. The suspension was centrifuged at 4,000rpm for $10 \mathrm{~min}$ and the upper grayish layer was discarded. Sediment containing white starch layer was collected and washed with distilled water over muslin cloth. Washings were then again centrifuged at 4,000 rpm for another 10 min and the upper grayish protein layer was removed and the starch layer was collected and washed with distilled water. Washed starch was treated with $1 \mathrm{M} \mathrm{HCl}$ and allowed to stay for $30 \mathrm{~min}$ and neutralized with $0.2 \mathrm{M} \mathrm{NaOH}$ solution. The solution was then filtered through a Buchner funnel and oven dried at $50^{\circ} \mathrm{c}$ for $120 \mathrm{~min}$ and starch powder was collected and allowed to pass through 120 mesh sieve and stored at room temperature [15-18].

\section{Chemical modification of bora rice starch}

The isolated Assam bora rice starch was modified by esterification of rice starch with thioglycolic acid. The reaction was carried out with 2 moles of thioglycolic acid for every 1 mole of the hydroxyl group in starch. Starch $(5 \mathrm{~g})$ was dissolved in $40 \mathrm{ml}$ of hot water. $1.8 \mathrm{ml}$ of $80 \%$ thioglycolic acid and $2 \mathrm{ml}$ of $7 \mathrm{~N} \mathrm{HCl}$ was added to this above solution. The mixture was allowed to react for $150 \mathrm{~min}$ at $80{ }^{\circ} \mathrm{C}$. The reaction mixture was poured into $500 \mathrm{ml}$ of methanol. Off white precipitates of thiolated starch so obtained were washed twice with methanol and dried at room temperature [19-21]. As thioglycolic acid is soluble in water and methanol, precipitation with methanol from an aqueous solution and subsequent washings by keeping precipitates over night was found to be a sufficient purification method for modified starch.

\section{Characterization of thiolated starch}

\section{Differential scanning calorimetry (DSC)}

DSC thermograms of native starch and modified starch were recorded using a differential scanning calorimeter (Perkin Elmer 4000). About 5 mg of the sample were crimped in a standard aluminium pan and heated in a temperature range of $30{ }^{\circ} \mathrm{C}$ to $400{ }^{\circ} \mathrm{C}$ at a heating rate of $10^{\circ} \mathrm{C}$ per minute in a nitrogen atmosphere.

\section{Fourier transform infra-red spectroscopy (FT-IR)}

Starch and modified starch were subjected to FT-IR spectroscopy in a Fourier-transform infrared spectrophotometer (Bruker, Alpha) in the range of $4000-400 \mathrm{~cm}^{-1}$.

\section{Ex-vivo mucoadhesive potential}

A comparative mucoadhesive potential evaluation of native starch and modified starch was done by carrying out tensile tests employing texture analyzer (TA. XT Express, Stable Micro System). The analyser was equipped with different weight load cell. At room temperature, fixed amount (1g) of samples of each formulation was placed on the upper probe. Probe with freshly excised goat mucosal tissue was attached to the lower probe as a model membrane. During the measurement, the probe was lowered at a rate of 0.5 $\mathrm{mm} / \mathrm{s}$ until a contact with the model membrane at a constant force of $30 \mathrm{~g}$ obtained. The force of $30 \mathrm{~g}$ was maintained for $5 \mathrm{~min}$ and the upper probe was moved upwards at a rate of $5 \mathrm{~mm} / \mathrm{s}$. The force required to detach the sample from tissue was considered as an index of mucoadhesive potential [22].

\section{Nuclear magnetic resonance (NMR)}

Nuclear magnetic resonance spectroscopy of the Starch and modified Starch was carried out by using an NMR spectrometer (Bruker Avance II, $400 \mathrm{MHz}$ ). The Starch and modified Starch in powder form were scanned from 1 to $10 \mathrm{ppm}$ range under the following measurement conditions: Magnet 9.4 T superconducting Magnet; Probe-BBO $400 \mathrm{MHz}$, with Z-gradient, 2H lock; for observation of nuclei like $1 \mathrm{H}, 13 \mathrm{C}, 31 \mathrm{P}, 15 \mathrm{~N}$, etc. with $1 \mathrm{H}$ decoupling. Any of these nuclei can be fully automatically selected and optimally tuned and matched.

\section{Particle size distribution}

Modified Starch was dispersed in distilled water to get a stock solution of $1 \%(\mathrm{w} / \mathrm{w})$. The solution was then homogenized at 15,000 rpm and filtered twice. This dispersion was then swiftly transferred in the sample cell and particle size distribution was determined using Zeta Sizer (Nano ZS 90, Malvern Instruments, UK) with the help of software.

\section{In vitro degradation study}

The degree of degradation of modified starch was evaluated in different simulated fluids such as simulated body fluid (SBF), simulated nasal fluid (SNF) and in simulated gastric fluid (SGF). Thin films of modified starch prepared by a casting method and were placed in Petri dishes which contain simulated fluids. Then the Petri dishes were incubated for $15 \mathrm{~min}$ at $37^{\circ} \mathrm{C}$.

After a predetermined time interval, the films were withdrawn and weighed before and after drying and were studied for degradation characteristics such as swelling degree and weight loss [23, 24].

Swelling degree-The test was done by comparing the weight $\left(\mathrm{w}_{\mathrm{t}}\right)$ gained due immersion in simulated fluid with the original weight $\left(w_{0}\right)$ of the sample and was calculated by the equation below,

$$
\mathrm{SD}(\%)=\frac{\mathrm{Wt}-\mathrm{Wo}_{\mathrm{o}}}{\mathrm{Wo}} \times 100(1)
$$

Weight loss-The weight loss was measured in terms of percentage by calculating the difference between the dry weight $\left(\mathrm{w}_{\mathrm{d}}\right)$ of the sample after degradation and original weight $\left(\mathrm{w}_{0}\right)$ of the sample using the following equation,

$$
\text { WL }(\%)=\frac{W o-W d}{W_{0}} \times 100(2)
$$

\section{Formulation of oral mucoadhesive gel system-}

Irinotecan loaded oral mucoadhesive gel was prepared using modified bora rice starch. Mucoadhesive property of native starch and modified starch were evaluated by formulating gels using irinotecan as the model drug. In brief, Carbopol 934P (0.5\%, w/v), as a gelling agent was dispersed in aqueous solution of irinotecan $(0.6 \%, \mathrm{w} / \mathrm{v})$ that contain starch or modified starch $(10 \%, \mathrm{w} / \mathrm{v})$ as mucoadhesive agent and allowed to hydrate overnight followed by addition of triethanolamine.

\section{Characterization of prepared gel}

\section{Determination of viscosity}

The viscosity of irinotecan loaded gels containing native starch (NS) and modified starch (TS) was measured using a Brookfield Viscometer (Brookfield DV-E Viscometer) at various speeds using spindle 25 at a range of $25-30{ }^{\circ} \mathrm{C}$.

\section{Adhesive strength analysis}

The gel adhesiveness was performed by using a texture analyzer (TA. XT Express, Stable Micro System) in adhesive mode. The formulation was transferred into a beaker and a cylindrical probe was forced down into sample at a defined rate $(0.5 \mathrm{~mm} / \mathrm{s})$ of and to a defined depth $(10 \mathrm{~mm})$. At least three replicate analyses of the sample were taken at temperatures at $25^{\circ} \mathrm{C} \pm 0.5^{\circ} \mathrm{C}$ and from the force-time plot the adhesiveness (the work necessary to overcome 
the attractive forces between the surface of the sample and the surface of the probe) was derived.

\section{Ex-vivo bioadhesive strength}

The mucoadhesive potential of each formulation was determined by measuring the force required to detach the formulation from the mucosal tissue. Briefly, the freshly excised goat intestinal tissue was collected from a local slaughterhouse and used immediately after the collection. At the time of testing a section of the tissue was secured to lower probe having a surface area of $3.14 \mathrm{~cm}^{2}$. At the room temperature, fixed amount of sample of each formulation was placed on the upper probe and the probe was lowered down until the sample contacted the surface of the tissue. Immediately, a slight force was applied for $30 \mathrm{Sec}$ to ensure the intimate contact between the tissue and the sample and the mucoadhesive force was expressed as the minimal weights that detached the sample from the tissue surface [22].

\section{In vitro permeation study}

For in vitro permeation study a dialysis membrane was being mounted on the Keshary-Chien diffusion cell displaying a permeation area of $3.15 \mathrm{~cm}^{2}$. The receptor compartment was filled with Phosphate buffer $(\mathrm{pH}$ 6.8) and the receptor medium was maintained at $37 \pm 0.5{ }^{\circ} \mathrm{C} .1 \mathrm{~g}$ of gel formulation was placed in the donor compartment. At defined time interval, $1 \mathrm{ml}$ of sample was withdrawn from the acceptor compartment, replacing with the same volume of the pre-warmed receiver solution to maintain the sink condition for a period of $6 \mathrm{~h}$. The samples withdrawn were filtered and used for analysis using UV-visible spectrophotometer at 254 $\mathrm{nm}$.

\section{RESULTS AND DISCUSSION}

\section{Synthesis of the modified starch}

Thiolation of bora rice starch was achieved by the ester bond formation between the hydroxyl groups of starch with carboxyl groups of thioglycolic acid. The collected product was found to be off-white in colour and soluble in water with some heat. The average yield of this synthesis amounted to $72 \pm 3.78 \%$ of the utilized amount of the rice starch.

\section{Differential scanning calorimetry}

The DSC thermograms of native Starch and modified starch were presented in fig. 2. The DSC curve of starch shows an endotherm at $76.18^{\circ} \mathrm{C}$ with a heat of fusion $114.72 \mathrm{~J} / \mathrm{g}$. While the DSC thermograms of modified starch shows a sharp endotherm at $81.11^{\circ} \mathrm{C}$ with a heat of fusion $150.20 \mathrm{~J} / \mathrm{g}$. The shifting of the endothermic peak as well as the heat of fusion in DSC thermogram revealed the crystal nature and gave a partial approval of a modification of the bora rice starch, which was further confirmed by FT-IR and NMR studies.

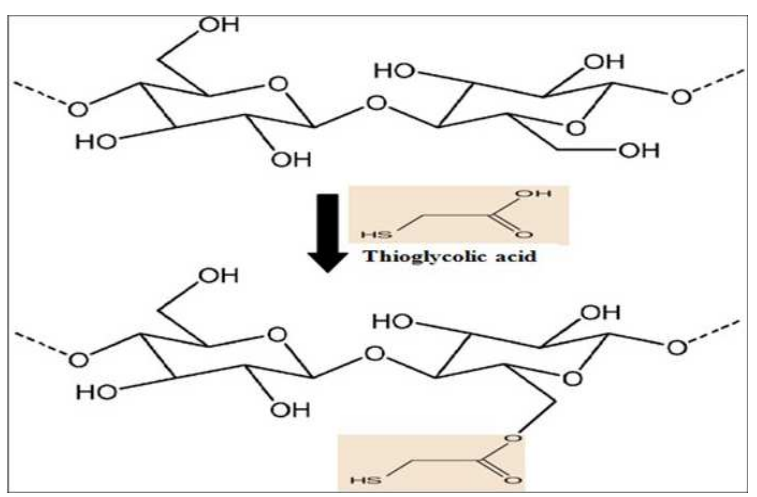

Fig. 1: Chemical synthesis of modified starch

\section{Fourier transform infrared spectroscopy}

The IR spectrum of native starch and modified starch showed in fig. 3 represented different stretch and bend vibrations with their respective peaks. The spectra of native starch display a characteristic broad peak at $3301.18 \mathrm{~cm}^{-1}$ representing hydroxyl ($\mathrm{OH}$ ) groups. Peaks at $2930.92 \mathrm{~cm}^{-1}$ attributed to $\mathrm{C}-\mathrm{H}$ stretching of alkanes. Peak appearing at $1151.21 \mathrm{~cm}^{-1}$ is due to (C-O-C) stretching of the cyclic ether. Coupled C-C stretching was confirmed by the peaks at $1001.43 \mathrm{~cm}^{-1}$. Whereas the IR spectra of modified starch shows the characteristic peak of thiol (-SH) group at $2625.07 \mathrm{~cm}^{-1}$ and hydroxyl group peaks at $2544.35 \mathrm{~cm}^{-1}$. C-H stretching of alkanes was confirmed by a peak at $1685.60 \mathrm{~cm}^{-1}$ while the peaks at 1154.43 $\mathrm{cm}^{-1}$ and $1006.44 \mathrm{~cm}^{-1} \mathrm{can}$ be attributed to $\mathrm{C}-0$ stretching of the ester group. From the peaks observed in their spectrum, it may be concluded that the polysaccharide starch undergo thiolation and presence of-SH stretch at $2625.07 \mathrm{~cm}^{-1}$ and more intensity of $\mathrm{C}=0$ stretch of ester confirms the modification.

\section{Ex-vivo bioadhesive strength}

The bioadhesive strength of native starch and modified starch were displayed in fig. 4 (a) and (b) respectively. The maximum force of a detachment of starch and modified starch from the intestinal mucosa under the same target force was found to be $46.3 \pm 6.79 \mathrm{~g}$ and $307.3 \pm 95.31 \mathrm{~g}$ respectively. Thus, it was suggested that the modified starch exhibits almost 6.6 fold higher mucoadhesive strength than native starch. The Greater mucoadhesive potential of modified starch compared to native starch could be associated with the formation of a disulfide bond between the-SH groups of modified polymers and mucus membrane. This potentiality of the modified starch encouraged us to explore it for mucoadhesive applications. The mucoadhesive property of native and modified starch was further comparatively evaluated preparing the gelling systems of both.

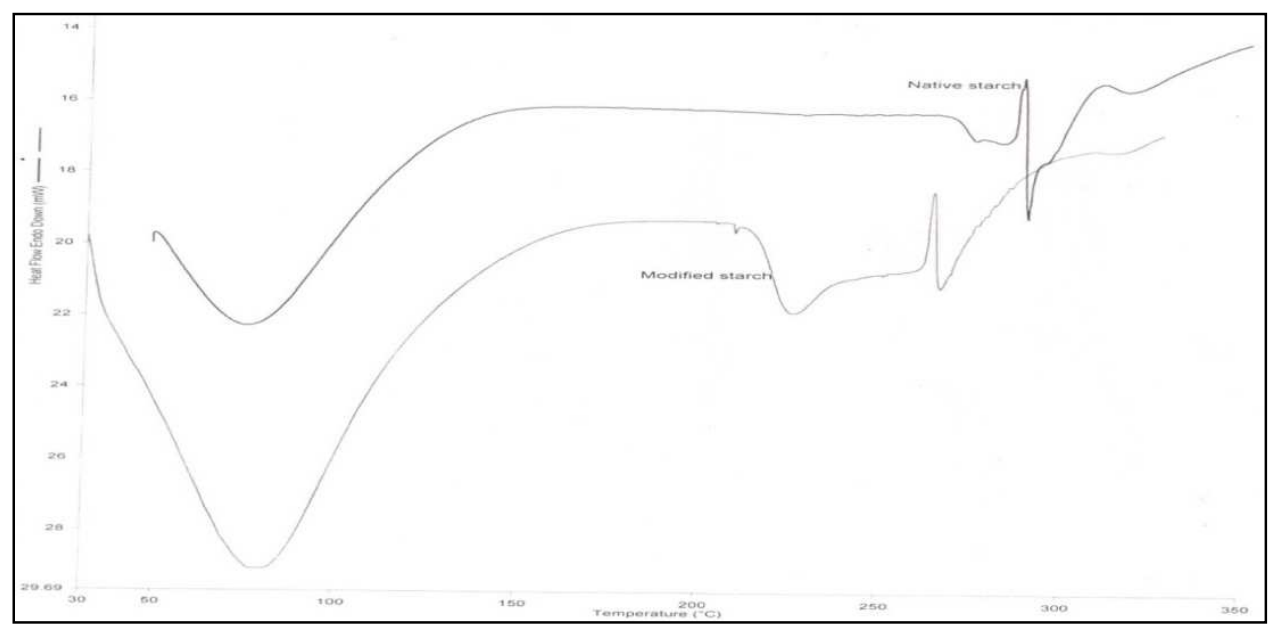

Fig. 2: DSC thermogram of native and modified starch 


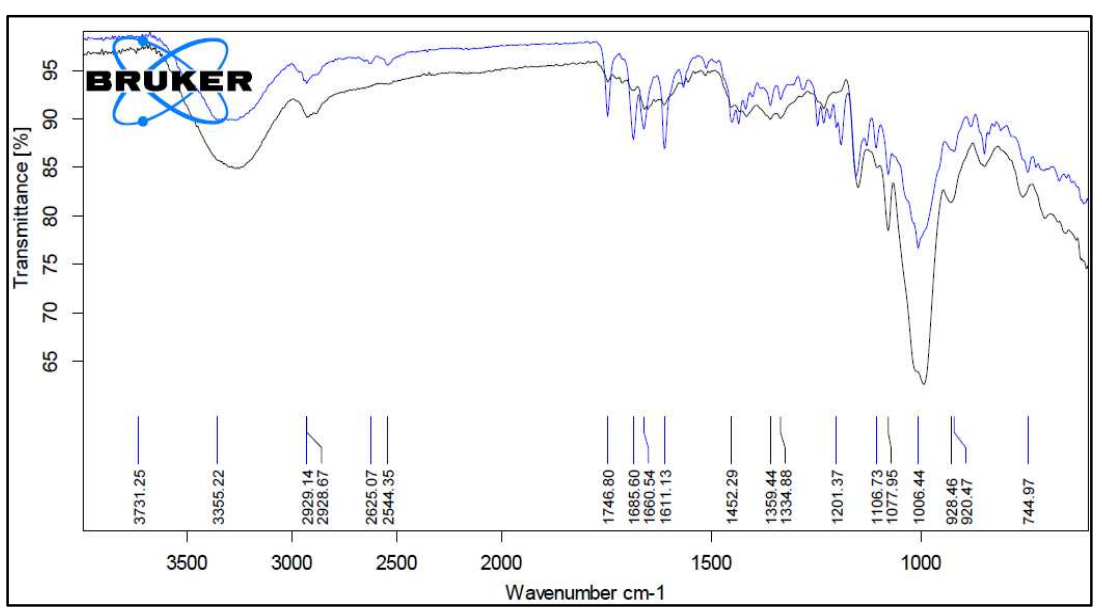

Fig. 3: IR spectra of native and modified starch

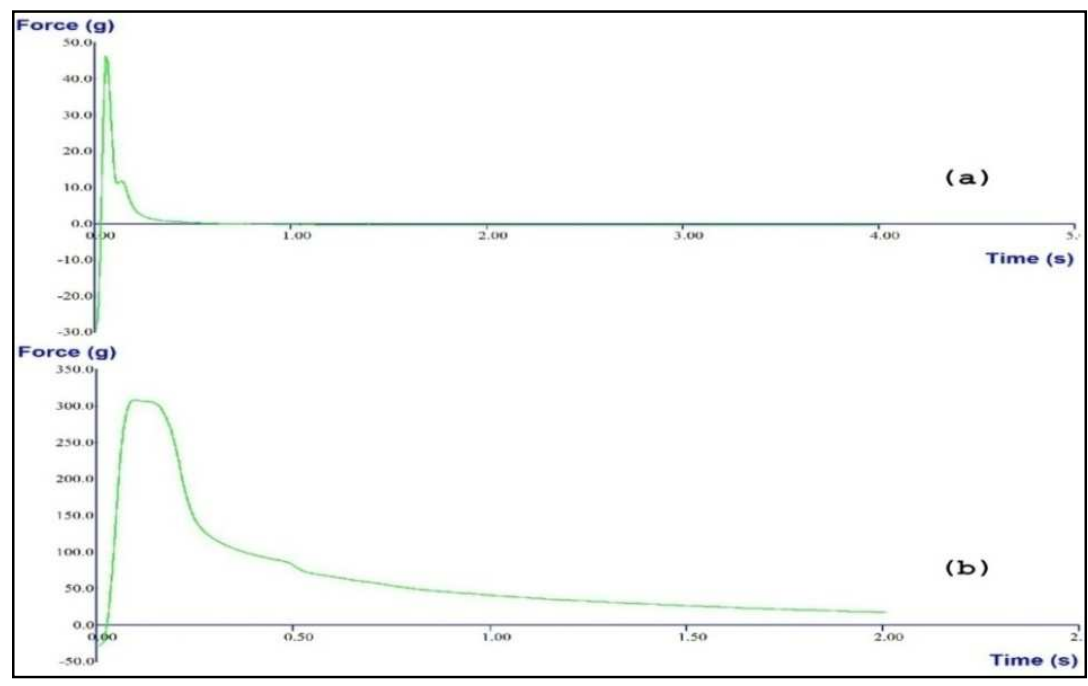

Fig. 4: Bioadhesive strength profile of native (a) and modified (b) starch

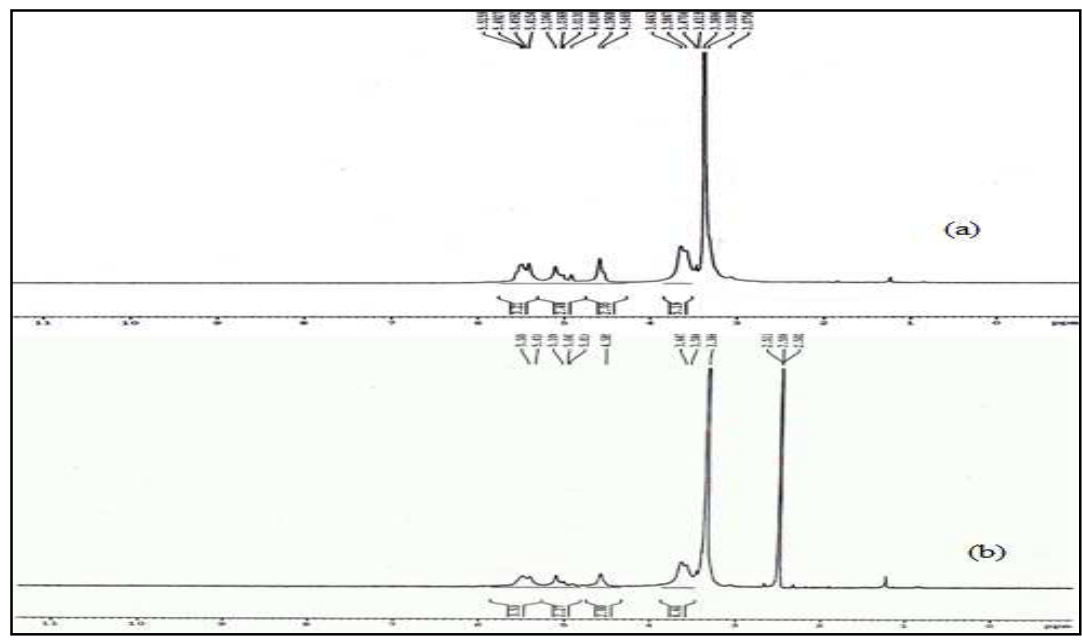

Fig. 5: NMR spectra of native (a) and modified (b) starch

\section{Nuclear magnetic resonance (NMR)}

To explore the possible modification of native starch, we studied the ${ }^{1} \mathrm{H}$ NMR spectra of both native starch and modified starch. As shown in fig. 5 (a) and (b), the majority of the native starch and modified starch shifts were between 2 and $6 \mathrm{ppm}$. In NMR spectra of starch, a singlet has been observed at $3.6\left(-\mathrm{O}^{-\mathrm{CH}_{2}}-\right.$ ). Another singlet at 4.59 for- $\mathrm{O}-\mathrm{CH}-$ and multiplets at 4.54 for $-\mathrm{O}-\mathrm{CH}_{2}-\mathrm{OH}$ also been found. 
Multiplets at 3.47 and a singlet at 5.1 appeared due to- $\mathrm{CH}-\mathrm{OH}$ and 0 -respectively. In case of modified starch the spectra was observed almost similar to native starch, but appearance of a new singlet at 2.50 due to- SH was found which confirms the success of the thiolation.

\section{Particle size distribution}

The average particle size and polydispersity index (PDI) of modified starch were determined as it could be explored for nanoparticular applications. The PDI is a dimensionless number that indicates the width of the size distribution. The Z-average value for modified starch was found to be $312.4 \pm 10.01 \mathrm{~nm}$ and the PDI was reported to be $0.534 \pm 0.05$. The particle size analysis provided a convincing approach for the modified starch to be used as other novel (nanoparticulate) carriers.

\section{In vitro degradation study}

In vitro swelling study represented the ability of the film to swell and revealed the sensitivity of both the native and modified starch in different simulated $\mathrm{pH}$. The degree of swelling was found to be higher in SBF than SNF followed by SGF. While the weight loss in SGF found to be lower than other fluid. The film is swollen, less in SGF and the weight loss also lower in SGF.

According to the results, the higher degree of swelling in SBF indicates that the modified starch film is highly swollable in respective fluid and possesses faster weight loss that was mainly due to the breakdown of the starch molecules

\section{Characterization of the gelling system \\ Determination of viscosity}

The results of the viscosity study were presented in table 1 . The viscosity of the modified starch based gel (MSG) and native starch based gel (NSG) were found to be $9950 \pm 636.39 \mathrm{cP}$ and $8899 \pm 799.03 \mathrm{cP}$ respectively at a defined speed of $5 \mathrm{rpm}$. The study revealed that the increased viscosity of the modified starch may be provided with a better-sustained release of drug from the matrix gelling system.

Table 1: Viscosity profile of oral mucoadhesive gel

\begin{tabular}{lll}
\hline \multirow{2}{*}{ RPM } & Viscosity(cP) $^{\#}$ & \\
\cline { 2 - 3 } & NSG* $^{*}$ & MSG** $^{* *}$ \\
\hline 0.5 & $43580 \pm 211.42$ & $48720 \pm 202.68$ \\
1 & $18720 \pm 756.60$ & $21300 \pm 49.49$ \\
3 & $13940 \pm 718.42$ & $17000 \pm 704.27$ \\
5 & $8899 \pm 799.03$ & $9950 \pm 636.39$ \\
\hline
\end{tabular}

All the values are represented as mean $\pm \mathrm{SD}(\mathrm{n}=3),{ }^{*} \mathrm{cP}-$ Centipoise, ${ }^{*}$ NSG-Native starch based gel, ${ }^{* *}$ MSG-Modified starch based gel

\section{Adhesive strength analysis}

An optimal gelling system must have the suitable adhesive strength (table 2) so that it can be retained at the mucosal surface for a longer period of time after administration. So during the development of such formulation, it is important to achieve the condition that allows in enhancing the residence time at the administration site. The adhesive strength for NSG and MSG was found to be $20.4 \pm 0.49 \mathrm{~g}$ and $43.5 \pm 8.90$ g respectively. In the case of modified starch gel, a marked increase in gel adhesiveness was observed and was measured as the area of the peak of the force-time curve.

Table 2: Gel adhesiveness and mucoadhesiveness profile of starch based gel

\begin{tabular}{lll}
\hline Formulation & Gel adhesion $(\mathrm{g})$ & Mucoadhesion $\mathbf{( g )}$ \\
\hline NSG $^{*}$ & $20.4 \pm 0.49$ & $18.8 \pm 1.82$ \\
MSG $^{* *}$ & $43.5 \pm 8.90$ & $37.0 \pm 1.69$ \\
\hline
\end{tabular}

All the values are represented as mean \pm SD $(n=3), *$ NSG-Native starch based gel, ${ }^{* *}$ MSG-Modified starch based gel

\section{Ex-vivo bioadhesive strength}

The bioadhesive strength of MSG and NSG was found to be $18.8 \pm 1.82$ g and $37 \pm 1.69$ g respectively (table 2 ). The results of the evaluation showed that the modified starch exhibit almost 2 folds better mucoadhesive property than the native starch formulation. The bioadhesive property of native starch may be due to the secondary hydroxyl $(\mathrm{OH})$ groups which could be considered as the main source of mucoadhesion while the better mucoadhesive strength of modified starch might be assigned with the covalent anchoring via disulfide bond formation of the modified starch with the mucus involving thiol exchange reaction.

\section{In vitro release study}

In vitro, drug release profiles were shown in fig. 5 . The MSG and NSG formulation showed $89.12 \pm 0.84 \%$ and $86.77 \pm 0.55 \%$ of drug release after $6 \mathrm{~h}$ of study in phosphate buffer $\mathrm{pH} 6.8$ respectively. The study revealed that no significant changes in the drug release pattern from modified starch and native starch, which indicate no change in gel network of both the starch which is supported by the viscosity study result showed in table 3 .

Although having the greater viscosity the divergence has been produced after observing the drug release study of the gel containing modified starch, which provided little faster release than the native starch based gel. This could be illustrated by taking help of the ex-vivo mucoadhesive study where the modified starch based gel showed a higher performance due to the formation of cross linking exhibited by disulfide bonds of the modified starch.

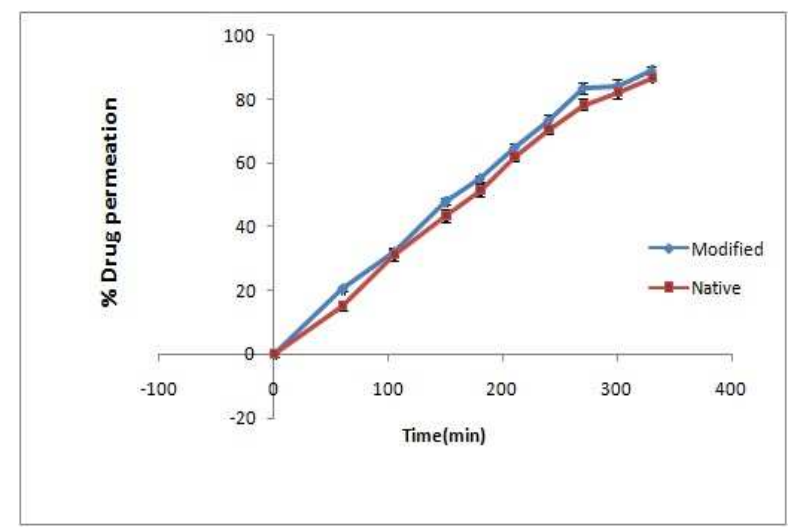

Fig. 6: In vitro release profile of both the gelling systems, All the values are represented as mean $\pm S D(n=3)$

Table 3: Comparative release kinetics parameter of irinotecan from different gelling systems

\begin{tabular}{lllll}
\hline Formulation & Zero & First & Higuchi's square root & Korsmeyer-peppas \\
\hline & $\mathrm{R}^{2} \mathrm{~K}$ & $\mathrm{R}^{2} \mathrm{~K}$ & $\mathrm{R}^{2} \mathrm{~K}$ & $\mathrm{R}^{2} \mathrm{~K} \mathrm{n}$ \\
NSG* $_{\text {MSG }}^{* *}$ & 0.99080 .281 & 0.95030 .005 & 0.96254 .360 & 0.99260 .4300 .922 \\
\hline
\end{tabular}

$\mathrm{n}=3$, * NSG-Native starch based gel, ${ }^{* *}$ MSG-Modified starch based gel 
The in vitro drug release data was applied in various kinetic models and the correlation coefficient (R) and the release rate constant were determined from the slope of the respective formulations that is shown in table 2. Both the formulations were found to be best fitted in the zero order model with $R^{2}$ value of 0.9822 and 0.9908 for MSG and NSG formulations respectively. Further, to confirm the drug release mechanism from the formulations, the in vitro drug release data at various time points were fitted into the KorsemayerPeppas equation. The correlation coefficient $\left(\mathrm{R}^{2}\right.$ values) of 0.9910 and 0.9926 for MSG and NSG respectively, and the release exponents ( $\mathrm{n}$ values) were found to be 0.854 and 0.922 respectively. The obtained $\mathrm{n}$ values of both the formulations were greater than 0.5 and less than 1 . Hence, it is revealed that the mechanism of drug release was a non-Fickian or anomalous diffusion [25].

\section{CONCLUSION}

On account of this study, it can be concluded that the isolated starch from Assam bora rice was successfully modified by thiol esterification method. The presence of thiol group in the modified starch was confirmed by FT-IR and NMR studies with the presence of peaks at $2626.74 \mathrm{~cm}^{-1}$ represents the-SH stretching and singlet appeared at 2.51 due to-SH group. DSC thermogram showed a sharp endothermic peak at $81.11^{\circ} \mathrm{C}$ that revealed the crystallinity of modified starch. The mucoadhesive strength of the gel was found to be $37 \pm 1.69 \mathrm{~g}$ and tensile strength found to be $43.5 \pm 8.90 \mathrm{~g}$. In vitro study showed $89.12 \%$ of drug release after $6 \mathrm{~h}$ at phosphate buffer $\mathrm{pH} 6.8$ and the release kinetics followed Non-Fickian diffusion. Thus, the modified bora rice starch can be used as a potential mucoadhesive excipient for the sustained release drug delivery system.

\section{ACKNOWLEDGEMENT}

The authors would like to thank Emcure Pharmaceuticals Ltd. (Pune, India) for providing Irinotecan as gift sample and the Girijananda Chowdhury Institute of Pharmaceutical Science for providing all the facilities for the study.

\section{AUTHOR CONTRIBUTION}

The authors meet the following conditions:

- Authors made valuable contributions to design, and/or acquisition of data, and/or analysis and interpretation of data.

- Authors also participated in drafting the article and revised it extensionally for its appropriate formatting.

\section{CONFLICT OF INTERESTS}

The authors declared no conflict of interest

\section{REFERENCES}

1. Bernkop-Schnürch A, Kast CE, Richter MF. Improvement in the mucoadhesive properties of alginate by the covalent attachment of cysteine. J Controlled Release 2001;71:277-85.

2. Vasir JK, Tambwekar K, Garg S. Bioadhesive microspheres as a control drug delivery system. Int J Pharm 2003;255:13-32.

3. Ahmed A, Bonner C, Desai TA. Bioadhesive micro devices with multiple reservoirs: a new platform for oral drug delivery. J Controlled Release 2002;81:291-306.

4. Bernkop-Schnürch A. Thiomers: a new generation of mucoadhesive polymers. Adv Drug Delivery Rev 2005;57:1569-82.

5. Gum JR, Hicks JW, Toribara J, Rothe NW, Lagace EM, Kim YS. The human MUC2 intestinal mucin has cysteine-rich subdomains located both upstream and downstream of its central repetitive region. J Biol Chem 1992;267:21375-83.

6. Bernkop-Schnürch A, Hornof M, Zoidl T. Thiolated polymersthiomers: synthesis and in vitro evaluation of chitosan-2-iminothiolane conjugates. Int J Pharm 2003;260:229-37.
7. Bernkop-Schnurch A, Steininger S. Synthesis and characterization of mucoadhesive thiolated polymers. Int J Pharm 2001;194:239-47.

8. Sachan KN, Bhattacharya A. Evaluation of Assam bora rice starch as a possible natural mucoadhesive polymer in the formulation of micro particulate control drug delivery systems. J Assam Sc Soc 2006;47:34-41.

9. Rajak P, Nath LK, Bhuyan B. Application of assam bora rice starch as a binder in the formulation of paracetamol tablets. Int J Pharm Pharm Sci 2014;6:118-20.

10. http://www.foodrepublic.com/2011/08/12/what-makessticky-rice-sticky. [Last accessed on 10 Apr 2017]

11. Sriamornsak P, Sungthongjeen S, Puttipipitkhachorn S. Use of pectin as a carrier for intragastric floating drug delivery: carbonate salt contained beads. Carbohyd Polym 2007;671:436-45.

12. Ahmed MZ, Akhter S, Ahmed I, Singh A, Anwar M, Shamim M, et al. In vitro and in vivo evaluation of Assam bora rice starchbased bioadhesive microsphere as a drug carrier for colon targeting. Expert Opin Drug Delivery 2011;9:1-9.

13. Putri KSS, Surini S, Anwar E. Pregelatinized cassava starch phthalate as a film-forming excipient for a transdermal film of ketoprofen. Asian J Pharm Clin Res 2013;6:62-6.

14. Liu H, Ramsden L, Corke H. Physical properties of cross-linked and acetylated normal and waxy rice starch. Starch-Starke 1999;51:249-52.

15. Li Y, Zhang H, Shoemaker FC, Xua Z, Zhud S, Zhonga F. Effect of dry heat treatment with xanthan on waxy rice starch. Carbohyd Polym 2013;92:1647-52.

16. Ackar D, Babic J, Subaric D, Kopjar M, Milicevic B. Isolation of starch from two wheat varieties and their modification with epichlorohydrin. Carbohyd Polym 2010;81:76-82.

17. Hasjim J, Li E, Dhital S. Milling of rice grains: Effects of starch/flour structures on gelatinization and pasting properties. Carbohyd Polym 2013;92:682-90.

18. Singh L, Sharma V, Sharma S. Preparation and characterization of modified starch isolated from amaranthus paniculatus linn. Int J Curr Pharm Res 2011;3:62-4.

19. Sharma R, Ahuja M. Thiolated pectin: synthesis, characterization and evaluation as a mucoadhesive polymer. Carbohyd Polym 2011;85:658-63.

20. Mahajan HS, Tyagi VK, Patil RR, Dusunge SB. Thiolated xyloglucan: synthesis, characterization and evaluation as mucoadhesive in situ gelling agent. Carbohyd Polym 2013;91:618-25.

21. Kaur H, Yadav S, Ahuja M, Dilbaghi N. Synthesis, characterization and evaluation of thiolated tamarind seed polysaccharide as a mucoadhesive polymer. Carbohyd Polym 2012;90:1543-9.

22. Martinac A, Filipovi c-Grcic J, Voinovich D, Perissutti B, Franceschinis E. Development and bioadhesive properties of chitosan-ethylcellulose microspheres for nasal delivery. Int J Pharm 2005;291:69-77.

23. Shi R, Zhu A, Chen D. In vitro degradation of starch/PVA films and biocompatibility evaluation. J Appl Polym Sci 2010;115:346-57.

24. Suggs LJ, Krishan RS, Garcia CA, Peter SJ, Anderson JM. In vitro and in vivo degradation of poly (propylene fumarate-co-ethylene glycol) hydrogel. J Biomed Mater Res 1998;42:312-20.

25. Ahmed AB, Nath LK. Design and development of controlled release floating matrix tablet of Nicorandil using hydrophilic cellulose and $\mathrm{pH}$-independent acrylic polymer: in vitro and in vivo evaluations. Expert Opin Drug Delivery 2016;13:315-24.

\section{How to cite this article}

- Abdul Baquee Ahmed, Iman Bhaduri. Chemical modification, characterization and evaluation of mucoadhesive potentiality of Assam bora rice starch. Int J Pharm Pharm Sci 2017;9(9):132-137. 